\title{
Investigation on Microstructure and Mechanical Properties of AA 2017A FSW Joints
}

\author{
Dorota Kocanda ${ }^{1, a}$, Janusz Mierzynski ${ }^{2, b}$, Janusz Torzewski ${ }^{3, c^{*}}$ \\ 1,2,3 Military University of Technology, 2 Witolda Urbanowicza Street, 00-908 Warsaw, Poland \\ adorota.kocanda@wat.edu.pl, bjanusz.mierzynski@wat.edu.pl, c janusz.torzewski@wat.edu.pl
}

\section{Keywords: FSW, FSW Joints, 2017A Aluminum Alloy, Mechanical Properties}

\begin{abstract}
The present paper aims to analyse the microstructure, mechanical properties and fatigue behavior of FSW butt joints. The influence of welding parameters on the quality of butt welds was appreciated in the macro and micro scales on the basis of observations made by means of a confocal microscope. Mechanical properties and HCF fatigue behavior of both the AA 2017A parent material and FSW butt welded specimens were examined experimentally. Tensile properties such a yield strength, ultimate tensile strength and elongation were derived as well. The results of tensile examinations of FSW butt joints were presented in the form of stress-strain curves. On the basis of microstructure analysis and tensile strength tests carried out for FSW butt joints manufactured at few sets of process parameters the most favorable parameters of FSW process were selected. Then, HCF tests were carried out under selected FSW process parameters for the samples either made of wrought material (parent material) or its butt joints. The results of the HCF tests were displayed such as the comparative plots drawn for the AA 2017A alloy specimen and its FSW butt joints.
\end{abstract}

\section{Introduction}

Aluminum alloys find application in various industries, namely aviation, aerospace, automotive, maritime and rail industries [1,2]. These alloys belong to structural materials that meet an increased requirements of modern industry and an environmental protection. Low density of aluminum alloys $\left(2.7 \mathrm{Mg} / \mathrm{m}^{3}\right)$, one third of that of steel, allows to significantly reduce the total weight of a structure, and therefore reduce its production costs, fuel consumption and exhaust gas production as well as $\mathrm{CO}_{2}$ emissions during operation. The accessibility of aluminum in nature, its price, plasticity and high machining of the structural elements make aluminum alloys competitive with modern composites. These issues have become the criteria in the selection of material as well as the development of efficient technologies for joining structural elements in many industries.

Among the available aluminum alloys (1XXX to $7 \mathrm{XXX}$ series), the $2 \mathrm{XXX}$ series alloys exhibit the highest static and fatigue strength due to the high copper content (2.9-3.5\%) in the chemical composition of alloys, which increases the mechanical properties and the precipitate mechanism of material strengthening. It also increases hardness, formability and material strength at elevated temperatures. Copper reduces corrosion resistance, ductility and weldability [3]. Additionally, a critical review of the advancements in joining methods of aluminium alloys has been performed. Aluminum alloys of the $2 \mathrm{XXX}$ series are materials that are difficult to weld by conventional methods due to their high thermal conductivity which is about four times that of low-carbon steel. However, the high thermal conductivity of aluminium alloy helps to solidify the molten weld pool of aluminium and, consequently, facilitates out-of-position welding. The strength of welded joints is at the level of $50-90 \%$ of the strength of the parent material, due to the brittleness and porosity of the weld and the tendency to microcracks development [4].

(c) (1) Content from this work may be used under the terms of the Creative Commons Attribution 3.0 license. Any further distribution of this work must maintain attribution to the author(s) and the title of the work, journal citation and DOI. Published under license by Materials Research Forum LLC. 
In order to increase the strength of aluminum joints in 1991, the British Welding Institute (TWI) developed and patented a competitive and ecological technology of frictional joining of aluminum components with material mixing within the weld, known as FSW (Friction Stir Welding) [5] FSW is a solid-state joining process with many advantages, such as robust mechanical and fatigue properties and a narrow heat-affected zone compared with conventional fusion welding [6-7]. The influence of FSW welding parameters on the microstructure changes in the combination of $3 \mathrm{~mm}$ thick flat rectangular samples from the AA2024-T8 alloy and the greatness of the generated deformations as well as mechanism of quasi-static cracking of the alloy AA2024-T8 under the influence of stretching was investigated in [8] as well. Effect of rotation speed $(400,600,800,1000,1250$ and $1500 \mathrm{rpm})$ at a constant welding speed (50 $\mathrm{mm} / \mathrm{min}$ ) on microstructure, hardness distributions and tensile properties of the AA2024-T3 alloy plates of 3mm thickness and their FSW joints were analyzed in [9]. It was turned out that increasing rotation speed resulted in finer and more homogenous distribution of second phase particles in the stir zone. A study of fatigue crack growth behavior of FSW welded butt joints of AA2024-T3 aluminium commonly used in riveted aeronautic fuselage structures was presented in [10]. There, is a need to join components with different thicknesses (3.8 $\mathrm{mm}$ and $4 \mathrm{~mm}$ ) using FSW. Crack growth tests on these joints are not standard. Fatigue crack growth rate was analyzed in different zones of the FSW welded joint and in parent material. Paper [11] review the latest developments in the FE numerical analysis of FSW processes, microstructures of FSW joints and properties of FSW welded structures made of different aluminium alloys. Some important numerical issues such as materials flow modeling under heat inputs, meshing procedure, temperature and residual stress distributions in the particular zones of FSW joints and failure criteria are discussed. Authors of the paper [12] paid attention only on the shear zone of a FSW weld considering a mechanism acted there. It can be observed that material in this zone is subjected to different thermo-mechanical cycles. They ask the question, whether this mechanism of shear zone formation results from a temperature increase with higher rotation speed and/or material held for an increased time at temperature, is still not understood. The study does give insight into the often conflicting results published regarding the microstructural evolution in a FSW of AA 2XXX- age hardened alloys.

\section{Experimental procedure}

Rectangular plates of dimensions 500x100 mm were cut out from $5 \mathrm{~mm}$ thick AA 2017A-T4 heat treated aluminium alloy sheet parallel to its rolling direction. Chemical composition of the aluminium alloy of wchich the specimen was made is presented in Table 1.

Table 1. Chemical composition

\begin{tabular}{lllllllll} 
wt. \% & $\mathrm{Si}$ & $\mathrm{Fe}$ & $\mathrm{Cu}$ & $\mathrm{Mn}$ & $\mathrm{Mg}$ & $\mathrm{Cr}$ & $\mathrm{Zn}$ & $\mathrm{Ti}$ \\
\hline 2017A & $0.2-0.8$ & $0.6-0.8$ & $3.5-4.5$ & $0.4-1$ & $0.4-0.8$ & $0.1-0.12$ & $0.23-0.27$ & $0.17-0.23$ \\
\hline
\end{tabular}

The plates have been butt welded parallel to their rolling directions by applying friction stir welding technique and the ESAB Legio 4UT professional device (Fig. 1a). The FSW tool geometry consisted of a threaded conical pin (diameters from 6.5 to $8.7 \mathrm{~mm}$ and height $4.8 \mathrm{~mm}$ ) and a spiral shoulder with a diameter of $19 \mathrm{~mm}$ (Fig. 1b). The tool has been tilted at an angle of 2 degrees. The joining process was carried out in the position of control mode.

Before joining process, the plates were subjected to grinding to remove alumina oxides from their surfaces by means of the grinding paper of different granularities. Then, the plates were cleaned. 


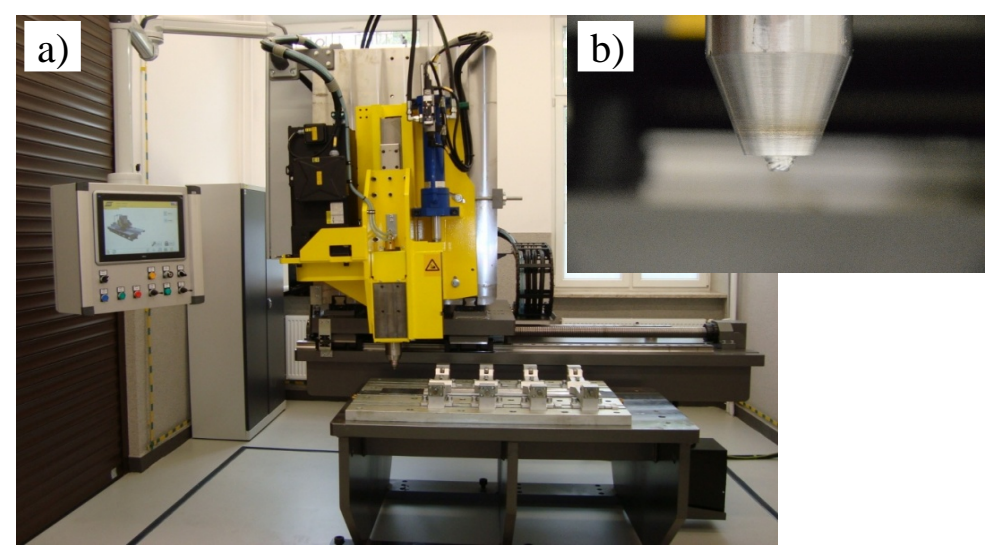

Fig. 1. The ESAB Legio $4 U T$ device (a) and FSW tool geometry (b)

Four different combinations of joining parameters were used in the studies. The welding parameters are provided in Table 2.

Table 2. Welding parameters used in the experiments

\begin{tabular}{c|rrcc}
\hline Material & \multicolumn{3}{|c}{ Rotation speed [rpm] } & - Welding speed [mm/min] \\
\hline AA 2017A-T4 & $500-200$ & $500-400$ & $350-200$ & $350-400$ \\
\hline
\end{tabular}

In order to derive mechanical and fatigue properties the specimens of geometry prepared according to ISO 6892-1:2009 were cut out from the welded plates perpendicular to the welding line. The way of taking specimens from the sheet and their sizes are shown in Fig. 2. The test specimens were not specially prepared except for the removal of the material that had flowed out at the joint. The surface from the front of the joint was remained after the joining process (Fig.7).

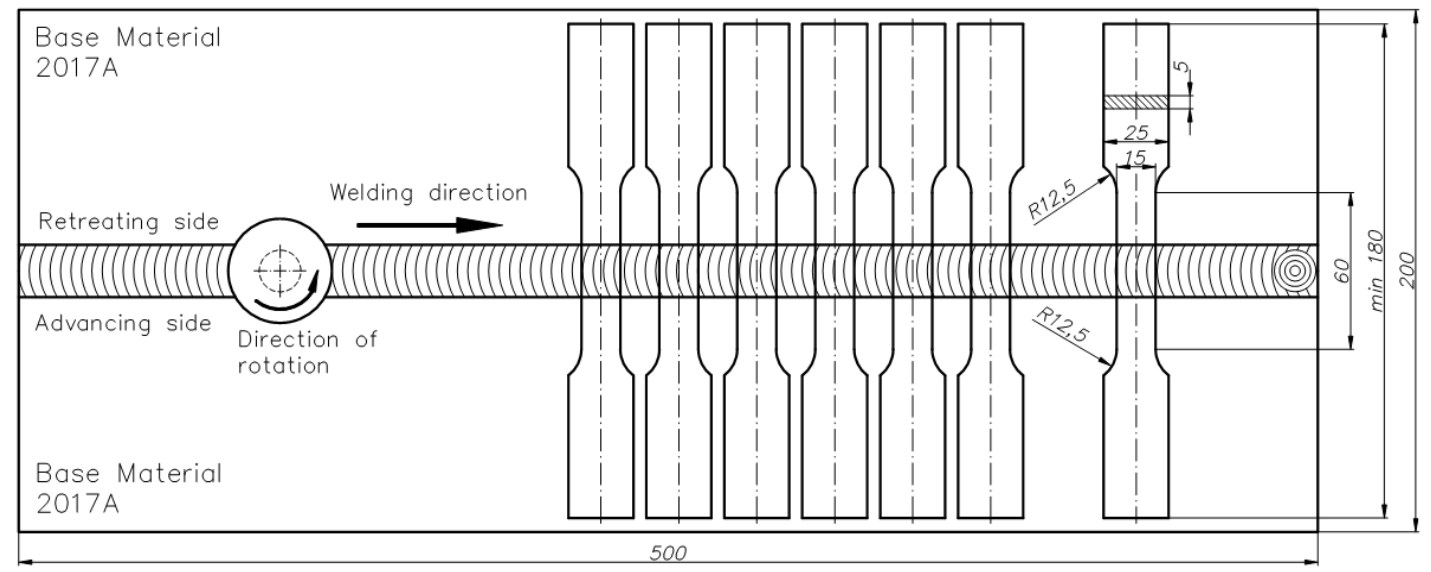

Fig. 2. Arrangement of AA 2017A sheets at the time of making FSW joints and dimensions of specimens in $\mathrm{mm}$ used for strength tests

Metallographic analyses were conducted on the specimen's cross-sections perpendicular to the welding direction. The cross-sections of specimens were polished using 3 and $1 \mu \mathrm{m}$ diamond solution and then etched with reagent consist of hydrofluoric acid, nitric acid and water for about 10 s. Observations of the base material and the welds were carried out using the Olympus LEXT OLS 4100 laser scanning confocal microscope. The Vickers hardness measurements were carried out in the cross-section of the joint in the centre of the specimen thickness using the Struers Dura Scan 70 device. The load of $0.98 \mathrm{~N}$ was applied for $10 \mathrm{~s}$ at a measuring point spacing of $0.5 \mathrm{~mm}$. 
Tensile and fatigue tests were carried out on an INSTRON 8802 universal testing machine with WaveMatrix computer software. Fatigue life tests were carried out under constant load amplitude control, at $\mathrm{R}=0.1$ and $12 \mathrm{~Hz}$ frequency. Fatigue failure was used as a criterion for the end of the test.

\section{Experimental results}

The FSW joints of the AA 2017A-T4 plates under examinations, obtained at four different combinations of process parameters were subjected to microstructural analysis.

Fig. 3 presents a macroscopic image of the FSW weld made at $500 \mathrm{rpm}$ of rotation speed and $200 \mathrm{~mm} / \mathrm{min}$ of welding speed. It can be observed there that the weld arose as an effect of the simultaneous actions of complex thermomechanical processes. As a result, the microstructure was modified in particular zones of joints. In their central part of the weld is located the nugget zone (NZ) where the mechanical-thermal interactions were the greatest and the phenomenon of dynamic recrystallization occurred. As a consequence, there was found a fine-grained microstructure with even-axial grains, the size of which ranged from 4 to $6 \mu \mathrm{m}$ (Fig. 4a). The shape of this zone and its microstructure strongly depended on the parameters of the joining process used. Three other characteristic zones of the weld, symmetrically located in relation to the nugget zone (NZ), can be clearly distinguished in the cross-section of the FSW joint. There are thermo-mechanical affected zone (TMAZ), heat affected zone (HAZ) and base material (BM).

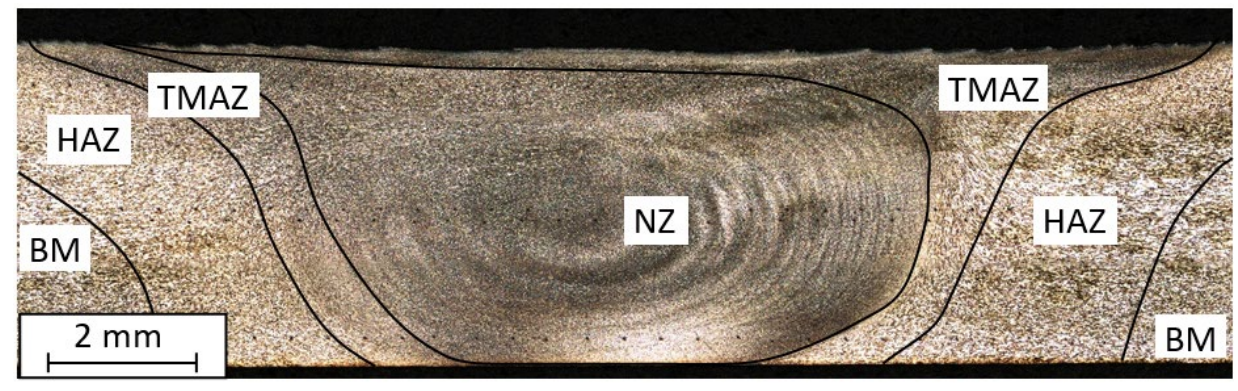

Fig. 3. Macrograph of the FSW joint cross-section referred to the welding parameters: $n=500$ $\mathrm{rpm}$ and $v=200 \mathrm{~mm} / \mathrm{min}$

In Fig. 4a-d magnified images of the mentioned zones, namely NZ, TMAZ, HAZ and to the base materials (BM) of AA 2017A alloy are showed. In the adjacent to the nugget zone a narrow thermo-mechanical affected zone was created. In this area the material has been subjected to both a strong mechanical deforming action of the microstructure grains and a thermal action changing the mechanical properties of the material. However, the thermal impact was not as high as in the case of the NZ so no recrystallization process was observed.

The image of the transition zone from NZ to TMAZ is shown in the picture in Fig. 4b. At a greater distance from the NZ, the mechanical impact on the material was smaller. However, a strong influence of temperature was still observed. This was reflected in the image of the microstructure shown in Fig. 4c and called as heat affected zone HAZ. In this zone no visible signs of plastic deformation were observed, nonetheless, the grain size of the microstructure is clearly larger than in the base material (BM). The microstructure of the base material presented in Fig. 4d was characterized by a clear texture resulting from the rolling of sheets in the production process. 

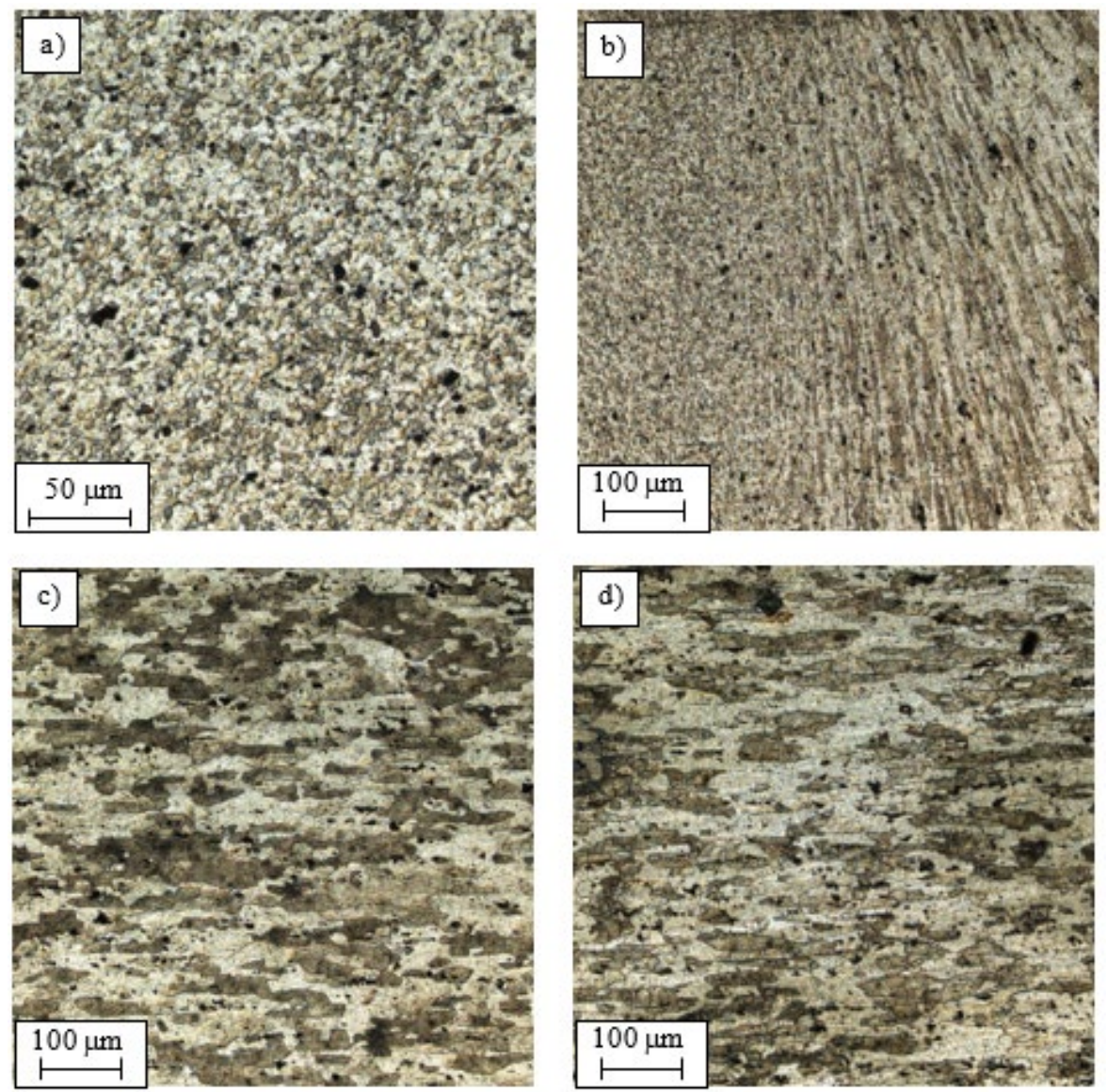

Fig. 4. Microstructures observed in the characteristic zones of the FSW joint: nugget zone (a), thermo-mechanical affected zone (b), heat affected zone (c) and base material (d).

The results of Vickers microhardness tests conducted along the cross-section of joints for three different sets of FSW process parameters are shown in Fig. 5. The measurements were carried out in a line lying in the middle of the sample thickness. The microhardness profile is characteristic for aluminium alloys showing precipitated hardening. One can notice in the joint area a significant decrease in the microhardness course below the microhardness of the base material of value equal to $134 \mathrm{HV}_{0.1}$ (horizontal dashed line in the graph). This drop is attributed to the dissolution of the alloy precipitated hardening as a result of the strong thermal pulse generated by the FSW process. The distribution of microhardness in the zones of the joints made at $\mathrm{n}=500 \mathrm{rpm}$ and welding speeds of 200 and $400 \mathrm{~mm} / \mathrm{min}$ respectively, resembles the letter "W", slightly offset from the central axis of the joint towards the retreating side of the weld. The minimum $\mu \mathrm{HV}$ values are between 116-118 $\mathrm{HV}_{0,1}$ on the material retreating side and around 120-121 $\mathrm{HV}_{0,1}$ on the advancing side. These ones are located in HAZ zones of the joint.

It is worth emphasizing that the microhardness in the nugget zone (NZ) is clearly higher than the minimum values, although it does not reach the $\mu \mathrm{HV}$ values typical for the base material. In the case of a joint made at $\mathrm{n}=350 \mathrm{rpm}$ and $\mathrm{v}=400 \mathrm{~mm} / \mathrm{min}$, the distribution of microhardness is different. The minimum hardness was obtained in the NZ zone and it fluctuated in the range of 98-115 $\mathrm{HV}_{0.1}$. Such a course of microhardness resulted from incorrect parameters of the FSW process for this alloy, which was confirmed by strength tests. 


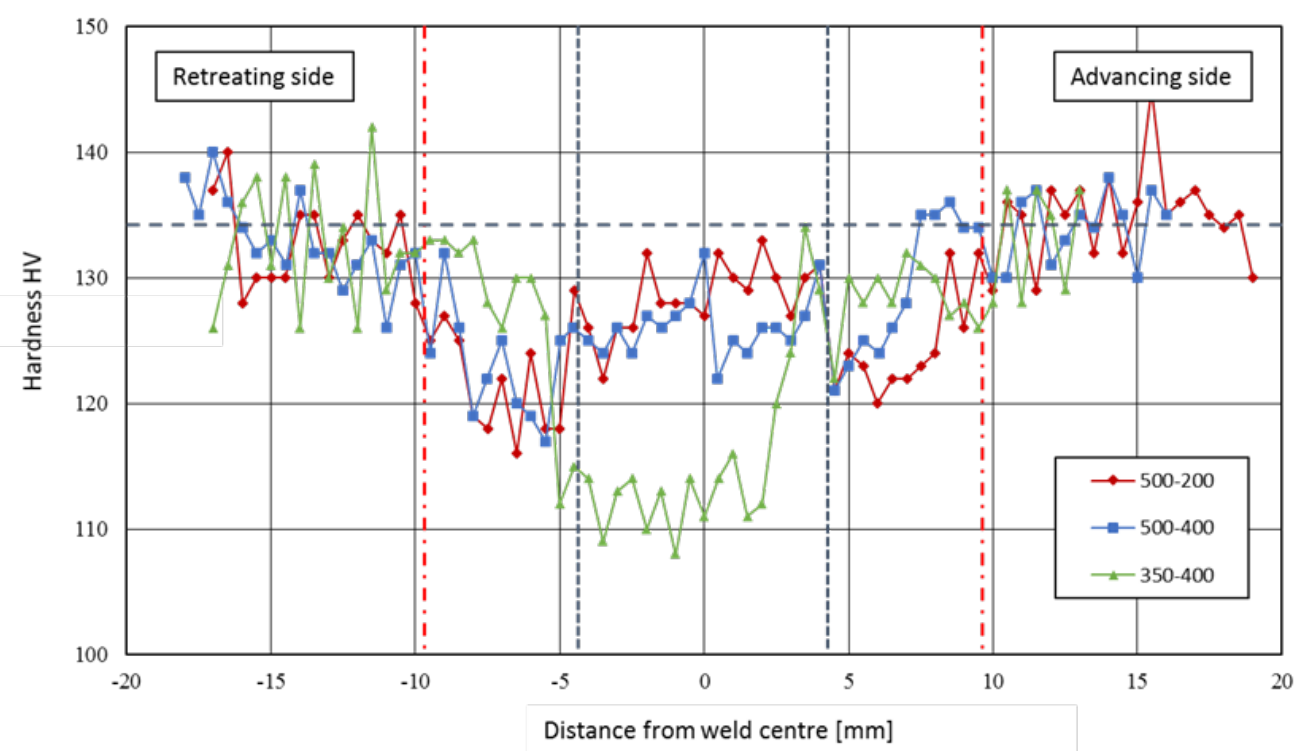

Fig. 5. Microhardness profiles across the FSW welds obtained from the specimens' crosssections at various welding parameters

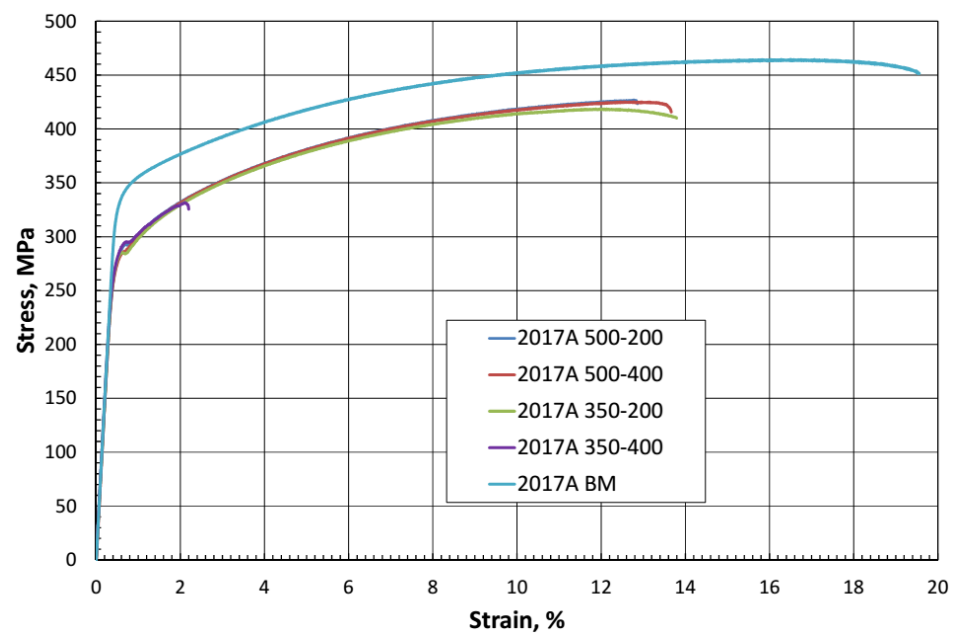

Fig. 6. Comparative plots of stress against strain derived from the tensile tests curried out for the AA 2017A-T4 alloy (base material) and its FSW butt joints at different values of process parameters

The monotonic tensile tests of the base material and butt joint specimens were carried out in order to identify the influence of joining parameters on the basic mechanical properties of standardized samples made of AA 2017A. The analysis of the test results made it possible to determine the basic mechanical parameters, i.e. offset yield stress $\left(R_{p 0 .}\right)$, ultimate tensile stress $\left(R_{m}\right)$ and relative elongation at break $(A)$. The results of strength tests in the form of stress-strain curves drawn both for the base material and for FSW welded samples manufactured at different process parameters are presented in Fig. 6. It can be noted that FSW butt welded specimens show a significant decrease in elongation at break (A) in relation to the parent material. This decrease of about $5.5 \%$ has been recorded for three sets of process parameters. In the case of the 
specimen welded at the parameters $\mathrm{n}=350 \mathrm{rpm}$ and $\mathrm{v}=400 \mathrm{~mm} / \mathrm{min}$, the mentioned above drop was even greater and the maximum deformation was only $2 \%$. The results of static tensile test conducted for the base material and FSW joints manufactured at four sets of process parameters are presented in Table 2 . Additionally, Table 2 shows the relative strength coefficient as the ratio of tensile strength of FSW joint $\left(\mathrm{R}_{\mathrm{mFSW}}\right)$ to the strength of the base material $\left(\mathrm{R}_{\mathrm{mB}}\right)$. This parameter clearly indicates that for a properly executed joint using the FSW method, a slight reduction of strength properties of amount 6-7\% is recorded. However, if the parameters have been wrongly selected, the decrease of strength properties was significant and amounted to about $27 \%$.

Table 2. Mechanical properties of AA 2017A

\begin{tabular}{|c|c|c|c|c|}
\hline & $\begin{array}{c}\mathrm{R}_{\mathrm{p} 0,2} \\
(\mathrm{MPa})\end{array}$ & $\begin{array}{c}\mathrm{R}_{\mathrm{m}} \\
(\mathrm{MPa})\end{array}$ & $\begin{array}{c}\mathrm{A} \\
(\%)\end{array}$ & $\mathrm{R}_{\mathrm{mFSW}} / \mathrm{R}_{\mathrm{mB}}$ \\
\hline 2017A Base Material & 330 & 450 & 19.0 & \\
\hline 2017A 500 - 200 & 285 & 425 & 13.0 & 0,94 \\
\hline 2017A 500-400 & 290 & 425 & 13.5 & 0,94 \\
\hline 2017A 350 - 200 & 285 & 420 & 13.5 & 0,93 \\
\hline 2017A 350 - 400 & 290 & 330 & 2.0 & 0,73 \\
\hline
\end{tabular}

Similar results were obtained for stresses corresponding to the offset yield stress $\left(\mathrm{R}_{\mathrm{p} 0.2}\right)$. The stresses in the welded samples were about $10 \%$ lower than in the base material for all sets of joining parameters (see Table 2).

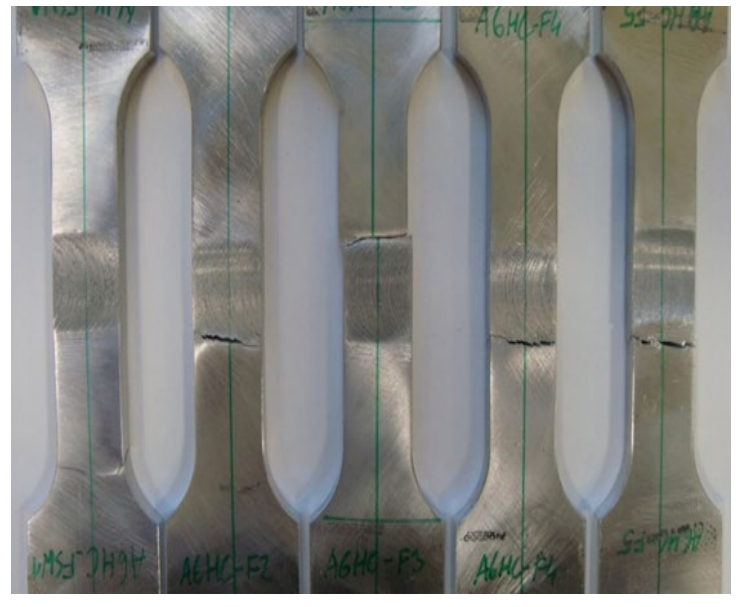

Fig. 7. General view of broken FSW welded samples after HCF tests.

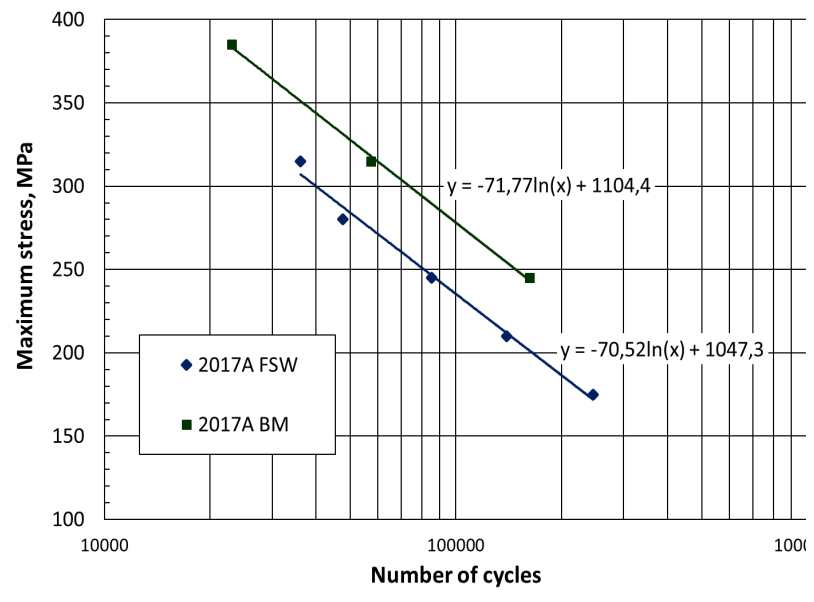

Fig. 8. HCF test results derived for wrought AA 2017A alloy and for FSW joints.

Preliminary HCF fatigue tests have been conauctea tor the Dase material as well as tor tne FSW welded specimens at $\mathrm{n}=500 \mathrm{rpm}$ and welding rate of $\mathrm{v}=400 \mathrm{~mm} / \mathrm{min}$. Fatigue tests were carried out in the limited fatigue life region at the stress ratio $\mathrm{R}=0.1$. The images of broken samples after HCF tests were showed in Fig. 7. It can be observed that the cracking process of the welded samples proceeded mainly in the weld and along the boundary between the hardened area and the parent material. This clearly proves the good quality of the FSW joint and the dominant of the structural notch effect over the technological notch. Comparative SN characteristics of HCF life seemed in Fig. 8 correspond to the samples made of base material (BM) and to FSW joints (FSW) and tested in the range of about $\mathrm{N}_{\mathrm{f}}=2 \cdot 10^{4} \div 3 \cdot 10^{5}$ number of 
cycles. The mentioned diagram indicates lower fatigue life of welded samples than this one for the parent material.

\section{Summary}

The study proved that FSW technology allows to obtain good quality joints featured by good strength properties for the 2017A aluminium alloy in a wide range of process parameters. The microhardness profiles measured along the specimens cross-sections showed characteristic shape "W" for aluminium alloys hardened by precipitates. Significant decrease in microhardness parameters was observed in the case of improperly selected joint parameters, as well. FSW joints manufactured at parameters $\mathrm{n}=500 \mathrm{rpm}$ and $\mathrm{v}=200 \mathrm{~mm} / \mathrm{min}$ were characterized by the best mechanical properties and microstructure. The study revealed that the ultimate tensile strength of FSW welded specimens reached $94 \%$ values of the strength corresponded to the base material. On the other hand, joints produced at parameters $n=350 \mathrm{rpm}$ and $\mathrm{v}=400 \mathrm{~mm} / \mathrm{min}$ showed poor mechanical and fatigue properties due to numerous defects resulting from improperly selected parameters of the joining process.

\section{References}

[1] J. Hirsch, Recent development in aluminium for automotive applications. Trans. Nonferrous Metals Soc. China 2014, 24, 1995-2002. https://doi.org/10.1016/s1003-6326(14)63305-7

[2] P. Rambabu, N.E. Prasad, V.V. Kutumbarao, R.J.H. Wanhill, Aluminium alloys for aerospace applications. In Aerospace Materials and Material Technologies; Prasad, N.E., Wanhill, R.J.H., Eds.; Springer: Singapore, 2017; pp. 29-52. https://doi.org/10.1007/978-98110-2134-3_2

[3] R. Rajan, P. Kah, B. Mvola et al., Trends in aluminium alloy development and their joining method, Rev. Adv. Mater. Sci., 44, (2016), 383-397.

[4] G. Cam, G. Ipekoglu, Recent development in joining of aluminium alloys, Int. J. Adv. Manuf Technol, December, 91, (2017), 1851-1816.

[5] W.M. Thomas, J.C. Nicholas, M.G. Needham, T. Smith, C.J Dawes,. Friction Stir Butt Welding. International Patent Application No. PCT/GB92/0220, December 1991

[6] R.S. Mishra, Z.Y. Ma, Friction stir welding and processing, Mater. Sci. Eng. R Rep. 50 (1-2) (2005) 1-78.

[7] H.J. Liu, H. Fujii, M. Maeda, K. Nogi, Tensile properties and fracture locations of frictionstir-welded joints of 2017-T351 aluminum alloy. J. Mater. Process. Technol. 2003, 142, 692696. https://doi.org/10.1016/s0924-0136(03)00806-9

[8] P. L. Threadgill, A. J. Leonard, H. R. Shercliff, P. J. Withers; Friction stir welding of aluminium alloys, Int Materials Reviews, vol. 54(2009), 49-93.

https://doi.org/10.1179/174328009x411136

[9] S. A. Khodir, T. Shibayanagi, M. Naka, Microstructure and mechanical properties of friction stir welded AA2024-T3 aluminium alloy, Mater. Transactions, 47,1, (2006), 185-193. https://doi.org/10.2320/matertrans.47.185

[10] P.M.G.P. Moreira, P.M.S.T de Castro, Fatigue crack growth on FSW AA2024-T3 aluminim joints, Key Engineering Materials, 498, (2012), 126-138. https://doi.org/10.4028/www.scientific.net/kem.498.126

[11] Xiaocong He, Fengshou Gu, A. Ball, a review of numerical analysis of friction stir welding, Progress in Materials Science, 65, (2014), 1-66. https://doi.org/10.1016/j.pmatsci.2014.03.003

[12] J. Schneider, R. Stromberg, P. Schilling et al., Processing effects on the friction stir weld stir zone, Welding Journal, 01, (2013), 1-9. 